\title{
Genomic landscape of inflammatory breast cancer identifies potential actionable genetic alterations
}

\author{
François Bertucci ${ }^{1,2}$, Steven Van Laere ${ }^{3}$, Daniel Birnbaum ${ }^{1}$ \\ ${ }^{1}$ Laboratoire d'Oncologie Prédictive, Centre de Recherche en Cancérologie de Marseille (CRCM), Inserm, U1068, CNRS \\ UMR7258, Institut Paoli-Calmettes, Aix-Marseille Université, Marseille, F-13009, France \\ 2 Département d'Oncologie Médicale, Institut Paoli-Calmettes, Marseille, France \\ ${ }^{3}$ Department of Oncological Research, GZA Hospitals Sint-Augustinus, Antwerp, Belgium \\ Correspondence to: François Bertucci, email: bertuccif@ipc.unicancer.fr \\ Keywords: DNA repair, Inflammatory breast cancer, Next-Generation Sequencing, NOTCH \\ Received: April 15, $2020 \quad$ Accepted: June 26, 2020 \\ Published: June 30, 2020
}

Copyright: @ 2020 Bertucci et al. This is an open-access article distributed under the terms of the Creative Commons Attribution License 3.0 (CC BY 3.0), which permits unrestricted use, distribution, and reproduction in any medium, provided the original author and source are credited.

Inflammatory breast cancer (IBC) is the most aggressive clinical form of breast cancer. Despite therapeutic progresses, $\sim 50 \%$ of patients die from metastatic relapse. Since the last two decades, efforts have been made to better characterize IBC molecular biology and identify new therapeutic targets. High-throughput molecular analyses have been applied to clinical samples [1], mainly based on gene expression profiling [2]. But IBC remains insufficiently characterized because of the scarcity of the disease, the small size of diagnostic samples, and the heterogeneity of studies with respect to the composition of the IBC and non-IBC control groups. The four pioneering studies based on Next-Generation Sequencing (NGS) [3-6] concerned small series ( $<54$ IBCs), including both untreated primaries ( $<26$ cases) and pre-treated relapses. The number of tested genes varied between 50 to 255 in the three series studied by targeted NGS [3-5]. Few studies directly compared primary IBC and non-IBC, and the comparisons were not adjusted upon the molecular subtypes despite the imbalance between IBC and nonIBC and were not corrected for multiple tests. Two of the most recurrently mutated genes identified in IBC (TP53, $H E R 2 / E R B B 2$ ) were associated with molecular subtypes (i.e. triple-negative, HER2+, respectively). The main finding was an increased tumor mutational burden (TMB) in IBC translating in the presence of many actionable genetic alterations (AGAs) with low frequency. Recently, a larger and more homogeneous series was reported [7]. In a molecular subtype-adjusted analysis of 91 genes in non-pretreated primary tumors of 156 IBCs and 197 stage 3-4 non-IBCs, 17 genes were more frequently mutated in IBC, including - in decreasing order of frequency in IBC TP53, NOTCH2, MYH9, BRCA2, ERBB4, POLE, FGFR3, ROS1, NOTCH4, LAMA2, EGFR, BRCA1, TP53BP1, ESR1, THBS1, CASP8, and NOTCH1. The analysis was not corrected for multiple tests.
Based on these observations, we launched a large multicentric comparative NGS study of non-pretreated primaries from IBC and non-IBC patients treated in our institutions, pooled with publicly available NGS data [8]. IBC was clinically defined as T4d according to the consensus criteria. The whole series included 101 IBCs and 2,351 non-IBCs. The analysis focused on 756 different genes present in at least one targeted NGS panel used across the represented series. For the first time in literature, all comparisons of DNA copy number and mutational data were adjusted upon both the molecular subtypes and AJCC stage and were corrected for multiple tests. The genomic profiles were heterogeneous in IBC. The TMB was higher in IBCs than in non-IBCs, in agreement with the higher genomic instability and complexity of the disease. Higher TMB, combined with the relatively peculiar immune microenvironment of IBC $[9,10]$, suggests that immune checkpoint inhibitors warrant investigation in IBC. In agreement, we recently launched the PELICAN trial (NCT03515798), an international multicentric phase II study evaluating pembrolizumab in combination with neoadjuvant chemotherapy in HER2- IBC.

The 10 most frequently genes we found altered in IBCs were TP53 (63\%), HER2/ERBB2 (30\%), MYC (27\%), PIK3CA (21\%), BRCA2 (14\%), CCND1 (13\%), GATA3 (13\%), NOTCH1 (12\%), FGFR1 (11\%), and ARIDIA (10\%). We identified 96 genes differentially altered between IBC and non-IBC, including 95 more frequently altered in IBC such as TP53, genes involved in DNA repair (BRCA2) and NOTCH pathways, and only one $(P I K 3 C A)$ more frequently altered in non-IBC. Genes such as EZH2 and SMARCA4, involved in chromatin remodeling, were also more frequently altered in IBCs, providing a rationale for the evaluation of epigenetic modifiers. Interestingly, 37/96 differential genes were more frequently altered in metastases than in primaries of 
non-IBC patients, suggesting a possible link of these genes with proclivity to metastasize.

Ninety-seven percent of IBCs displayed at least one AGA. This percentage was higher than in nonIBCs $(87 \%)$. We analyzed six specific drug classes and functional pathways. In four classes, and even if the percentage of patients with AGAs in IBC did not remain significantly superior (classes of HER/EGFR inhibitors, of other tyrosine kinase receptors inhibitors, and of CDK4/6 inhibitors) or inferior (class of PI3K/AKT/ mTOR inhibitors) to that of patients with AGAS in nonIBC in multivariate analysis, the percentages were high in IBC patients. Such observation suggests that, like non-IBC patients, IBC patients may benefit from these inhibitors. Of note, an expression signature associated with sensitivity to palbociclib showed a higher score in IBCs than in non-IBCs.

Two functional pathways gave particularly interesting results. Several genes involved in DNA repair were more frequently altered in IBCs such as $A T M, A T R X$, BARD1, BRCA2, ERCC3, MSH2, MSH6, PMS2, and $P O L E$, confirming recent findings [7]. The percentage of patients with alterations of DNA repair genes was twice as high in IBC as in non-IBC (33\% versus 17\%). Such deficient DNA repair might contribute to IBC progression, as well as to the high TMB observed. We also found that IBCs showed more frequently ( 2.3 -fold more) a homologous recombination deficiency (HRD) score, supporting the development of PARP inhibitors in IBC.

Alterations in the NOTCH pathway were almost twice more frequent in IBC ( $30 \%$ vs $17 \%$ in non-IBC). $\mathrm{NOTCH} 1$ was the most frequently altered $\mathrm{NOTCH}$ gene in IBC $(12 \%)$, and $\mathrm{NOTCH} 2$, and NOTCH4 were more frequently altered in IBC compared with non-IBC, as reported [7]. We also found a $\mathrm{NOTCH}$ pathway activation score higher in IBC than in non-IBC. Thus, these results support a role for the NOTCH pathway in IBC, previously suggested from pre-clinical models, with for example the ability of a gamma-secretase inhibitor to block NOTCH signaling and to attenuate the stem-like phenotype of IBC cells [11]. NOTCH targeting might be a therapeutic option in IBC.

In conclusion, the genomic landscape of IBC is different from that of non-IBC, independently from molecular subtypes and stage. The high percentage of patients with AGA suggests that precision medicine is a bona fide option in this aggressive disease, notably with drugs targeting immune system, DNA repair, NOTCH signaling, and CDK4/6. Functional and clinical validation is warranted and clinical trials are ongoing. But clearly, analysis of larger series of IBC samples with larger-scale NGS (Whole-Exome Sequencing, WholeGenome Sequencing), RNA-Seq, epigenomics and other technologies is needed, though collaborative studies we launched. Such analyses will allow better assessment of structural variations, mutational signatures, clonality and epigenetic alterations and could reveal the etiology of this mysterious and devastating disease.

\section{CONFLICTS OF INTEREST}

The author declares no potential conflicts of interest.

\section{REFERENCES}

1. Bertucci F, Finetti P, Vermeulen P, Van Dam P, Dirix L, Birnbaum D, Viens P, Van Laere S. Genomic profiling of inflammatory breast cancer: a review. Breast. 2014; 23:538-45. https://doi.org/10.1016/j.breast.2014.06.008 PMID:24998451

2. Van Laere SJ, Ueno NT, Finetti P, Vermeulen P, Lucci A, Robertson FM, Marsan M, Iwamoto T, Krishnamurthy S, Masuda H, van Dam P, Woodward WA, Viens P, et al. Uncovering the molecular secrets of inflammatory breast cancer biology: an integrated analysis of three distinct affymetrix gene expression datasets. Clin Cancer Res. 2013; 19:4685-96. https://doi.org/10.1158/1078-0432. CCR-12-2549 PMID:23396049

3. Ross JS, Ali SM, Wang K, Khaira D, Palma NA, Chmielecki J, Palmer GA, Morosini D, Elvin JA, Fernandez SV, Miller VA, Stephens PJ, Cristofanilli M. Comprehensive genomic profiling of inflammatory breast cancer cases reveals a high frequency of clinically relevant genomic alterations. Breast Cancer Res Treat. 2015; 154:155-62. https://doi. org/10.1007/s10549-015-3592-z PMID:26458824

4. Hamm CA, Moran D, Rao K, Trusk PB, Pry K, Sausen M, Jones S, Velculescu VE, Cristofanilli M, Bacus S. Genomic and Immunological Tumor Profiling Identifies Targetable Pathways and Extensive CD8+/PDL1+ Immune Infiltration in Inflammatory Breast Cancer Tumors. Mol Cancer Ther. 2016; 15:1746-56. https://doi.org/10.1158/1535-7163. MCT-15-0353 PMID:27196778

5. Matsuda N, Lim B, Wang Y, Krishnamurthy S, Woodward W, Alvarez RH, Lucci A, Valero V, Reuben JM, MericBernstam F, Ueno NT. Identification of frequent somatic mutations in inflammatory breast cancer. Breast Cancer Res Treat. 2017; 163:263-72. https://doi.org/10.1007/s10549017-4165-0 PMID:28243898

6. Goh G, Schmid R, Guiver K, Arpornwirat W, Chitapanarux I, Ganju V, Im SA, Kim SB, Dechaphunkul A, Maneechavakajorn J, Spector N, Yau T, Afrit M, et al. Clonal Evolutionary Analysis during HER2 Blockade in HER2-Positive Inflammatory Breast Cancer: A Phase II Open-Label Clinical Trial of Afatinib +/- Vinorelbine. PLoS Med. 2016; 13:e1002136. https://doi.org/10.1371/journal. pmed.1002136 PMID:27923043

7. Liang $\mathrm{X}$, Vacher S, Boulai A, Bernard V, Baulande S, Bohec M, Bièche I, Lerebours F, Callens C. Targeted nextgeneration sequencing identifies clinically relevant somatic mutations in a large cohort of inflammatory breast cancer. Breast Cancer Res. 2018; 20:88. https://doi.org/10.1186/ 
S13058-018-1007-x PMID:30086764

8. Bertucci F, Rypens C, Finetti P, Guille A, Adélaïde J, Monneur A, Carbuccia N, Garnier S, Dirix P, Gonçalves A, Vermeulen P, Debeb BG, Wang X, et al. NOTCH and DNA repair pathways are more frequently targeted by genomic alterations in inflammatory than in non-inflammatory breast cancers. Mol Oncol. 2020; 14:504-19. https://doi. org/10.1002/1878-0261.12621 PMID:31854063

9. Bertucci F, Finetti P, Colpaert C, Mamessier E, Parizel M, Dirix L, Viens P, Birnbaum D, van Laere S. PDL1 expression in inflammatory breast cancer is frequent and predicts for the pathological response to chemotherapy. Oncotarget. 2015; 6:13506-19. https://doi.org/10.18632/ oncotarget.3642 PMID:25940795

10. Van Berckelaer C, Rypens C, van Dam P, Pouillon L, Parizel M, Schats KA, Kockx M, Tjalma WA, Vermeulen P, van Laere S, Bertucci F, Colpaert C, Dirix L. Infiltrating stromal immune cells in inflammatory breast cancer are associated with an improved outcome and increased PDL1 expression. Breast Cancer Res. 2019; 21:28. https://doi. org/10.1186/s13058-019-1108-1 PMID:30777104

11. Debeb BG, Cohen EN, Boley K, Freiter EM, Li L, Robertson FM, Reuben JM, Cristofanilli M, Buchholz TA, Woodward WA. Pre-clinical studies of Notch signaling inhibitor RO4929097 in inflammatory breast cancer cells. Breast Cancer Res Treat. 2012; 134:495-510. https://doi. org/10.1007/s10549-012-2075-8 PMID:22547109 